East African Medical Journal Vol. 87 No. 6 June 2010

MULTIFOCAL PHEOCHROMOCYTOMA IN EARLY CHILDHOOD: CASE REPORT

C. Yuko-Jowi, MBChB, MMed, Department of Paediatrics and Child Health, College of Health Sciences, University of Nairobi, P. O. Box 19676 - 00202, Nairobi, Kenya, R. Mukhwana, MBChB, MMed, (Paed.), Consultant Paediatrician, Gertrude's Garden Children's Hospital, P. O. Box 42325 - 00100, Nairobi, Kenya and F. E. Onyango, MBChB, MMed (Paed), Professor, Department of Paediatrics and Child Health, College of Health Sciences, University of Nairobi, P. O. Box 19676 - 00202, Nairobi, Kenya

Request for reprints to: Dr. C. Yuko-Jowi, Department of Paediatrics and Child Health, College of Health Sciences, University of Nairobi, P. O. Box 19676 - 00202, Nairobi, Kenya

\title{
MULTIFOCAL PHEOCHROMOCYTOMA IN EARLY CHILDHOOD: CASE REPORT
}

\author{
C.YUKO-JOWI, R. MUKHWANA and F. E. ONYANGO
}

\begin{abstract}
SUMMARY
A three and a half year old male with multifocal phaeochromocytoma involving the right adrenal gland and an intrathoracic mass is presented. Twenty four hour vanillylmandelic acid (VMA) was negative despite suggestive symptomatology. The diagnosis was made on serial CT scans of the head, thoracic inlet and pelvis. He underwent right adrenalectomy and thoracotomy to remove the abdominal and intrathoracic mass. The diagnosis was confirmed by histology. He remained hypertensive on hefty antihypertensive doses throughout his lifespan and finally succumbed to status epilepticus at the age of ten, six years from the time of diagnosis.
\end{abstract}

\section{INTRODUCTION}

Phaeochromocytoma is a rare tumour arising from the chromaffin tissue of the adrenal medulla and sympathetic ganglia (1). It was first described by Frankel in 1866 (2) subsequently Marchetti in 1904 reported the first postmortem case in a male child aged 15 years (3) while Robinson and Williams in 1956 discussed the disorder in childhood and described two cases. Since then many paediatric cases of unilateral, bilateral and extra-adrenal phaeochromocytoma have been reported in literature (4).

The true incidence of this disease in childhood is unknown. Data from developed countries gives an autopsy incidence of $0.3 \%$ with a prevalence of up to $10 \%$ in children alone (4). The tumour was thought to be rare in African subjects until 1967 when Somers et al (5) reported several cases at Mulago Hospital, none of which were in early childhood. The youngest child reported in literature was a boy aged five years who presented with hyperactivity, headache and diaphoresis (6). In 1973, Parkar (7) reported the first case in East Africa of a girl aged nine years who presented with sweating and visual disturbances sustained hypertension.

Generally history includes episodic sweating, headache, tachycardia and sometimes fever. The disorder may be familial and often multicentre and bilateral, with increased incidence of extra-adrenal tumours. The presence in young age may be part of various familial syndromes like multiple endocrine neoplasia (MEN) type II, IIa or llib or type III,
Von-Hippel Lindau disease, Von Recklinghausen syndrome and Sturge-Weber Syndrome. We report a patient who presented with episodes of sweating, headache, recurrent abdominal pains, convulsions and recurrent episodes of loss of vision. Terminally he had sustained severe systemic hypertension.

\section{CASE REPORT}

S.O. a $3^{1 / 2}$ year old male presented to the paediatric emergency unit of the Kenyatta National hospital with one day history of severe abdominal pains and sweating. Examination at this time revealed marked tenderness in the right flanks suggestive of acute appendicitis. He was admitted for emergency laparatomy and an appendicectomy performed was reported as congested. Post-operatively he did well and was discharged home after four days only to be re-admitted two days later in a semi-comatose state with a history of restlessness, excessive sweating, fever, convulsions, polyuria and polydipsia. There was no family history of hypertension. On examination, he was semi-comatose, and febrile, with a tachycardia of $144 \mathrm{~b} / \mathrm{min}$, blood pressure $90 / 60 \mathrm{mmhg}$. There was no jaundice, pallor, oedema or lymphadenopathy. The pupils were normal, neck was soft, and the kerning's sign negative. The cardiovascular, abdominal and respiratory examinations were unrevealing. An impression of malaria, to rule out meningitis was made and he commenced on rocephin, amikacin, quinine and phenobarbitone for the convulsions. Laboratory 
studies showed random blood sugars ranging from 2.8 to $27.5-\mathrm{mmol} / \mathrm{L}$, negative blood slide for malaria parasites, a raised cerebrospinal fluid protein of $1.4 \mathrm{~g} / \mathrm{L}$ with normal urea-electrolytes creatinine, calcium, phosphates and haemogram. HIV antibody screening was negative.

Day 2 after re-admission he came out of the semi comatose state but was noted to have lost his vision. An ophthalmic evaluation indicated a possibility of cortical blindness. Hedeveloped repeated convulsions while in the ward not responding to conventional anticonvulsants treatment. A repeat cerebrospinal fluid evaluation was non-rewarding brain CT scan done showed multiple infarcts in occipital and left temporal areas (Figure 1).

He completed the treatment of meningitis and was discharged after two weeks only to be readmitted after two days with history of visual hallucinations, sweating, vomiting, frequent convulsions and weakness of the right arm. This time physical examination showed right upper arm paresis and a low-grade fever of $37.6^{\circ} \mathrm{C}$. The blood pressure was normal but a haemogram showed a leucocytosis of $16800 / \mathrm{mm}$ cubed with neutrophils of $70 \%$, platelet count of $680000 / \mathrm{mm}$ cubed and ESR of $10 \mathrm{~mm} / \mathrm{hr}$. Coagulation screen done showed a hypercoaguable state with shortened prothrombin time and KCCT. Lupus anticoagulant test was negative. Herpes simplex encephalitis or a coagulation disorder was suspected and he was commenced on intravenous acyclovir, dexamethasone and phenobarbitone. The convulsions, hallucinations, recurrent loss of vision and fever disappeared, but episodes of sweating, headaches and abdominal pains persisted.

After five weeks of stay in the ward, a rise in the blood pressure was recorded $(220 / 150 \mathrm{mmHg})$ and this remained high raising the possibility of a phaeochromocytoma or renovascular hypertension. Further investigations ordered along this line. Urine for VMA, catecholamine and porphyrins were negative, thyroid function tests were normal, and haemoglobin electrophoresis showed a pattern of haemoglobin AA. A chest X -ray showed multiple right paracardiac masses (Figure2). Ultrasonography of urinary system was normal together with the liver and spleen. Intravenous urogram showed a delayed excretion of contrast in both kidneys, while echocardiography revealed a slightly dilated left ventricle with no coarctation of the aorta. A renal arteriogram and aortic root angiograms showed a suprarenal tumour blush while serial CT scans from the thoracic inlet to the pelvis showed two masses one on the right adrenal gland measuring $5 \times 4 \times 3$ $\mathrm{cm}$ and the other on right paravertebral intrathoracic region measuring $2 \times 2 \mathrm{~cm}$ (Figures 2 and 3).

Figure 1

Arrows in the serial CT scans A to D showing hypo-dense bi-occipital leucoencephalopathy

A

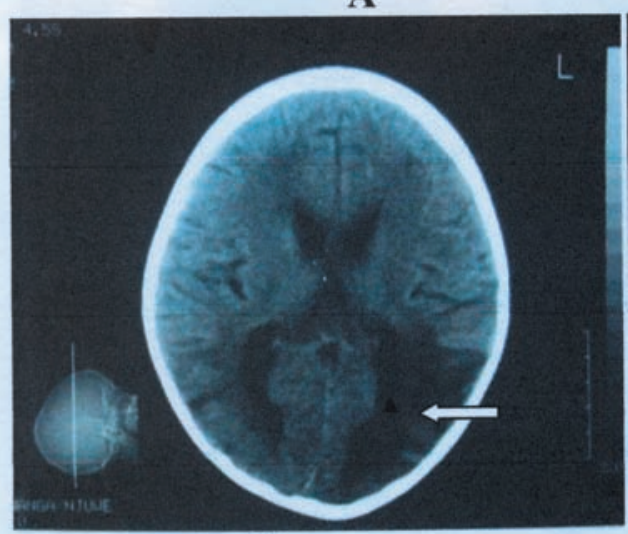

C

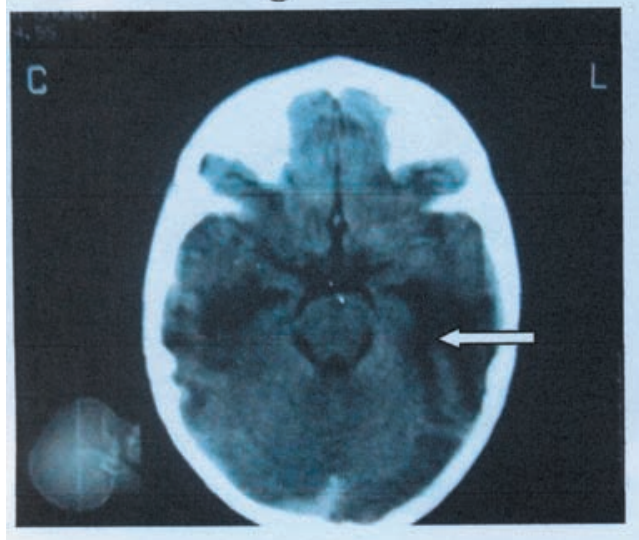

B

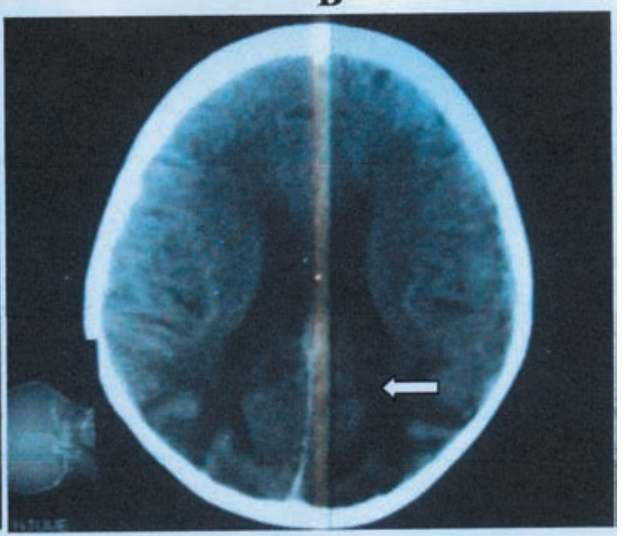

D

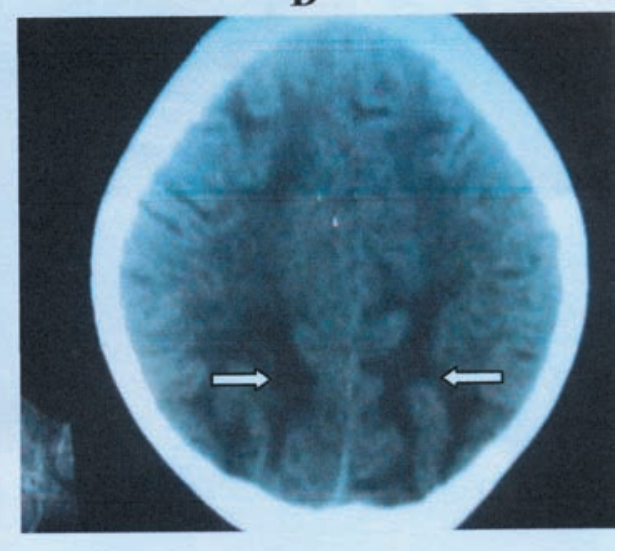


Figure 2

Chest radiograph. The arrow showing extensive right paracardiac pulmonary infiltrates suggestive of metastatic lesions. Right pleural effusion noted

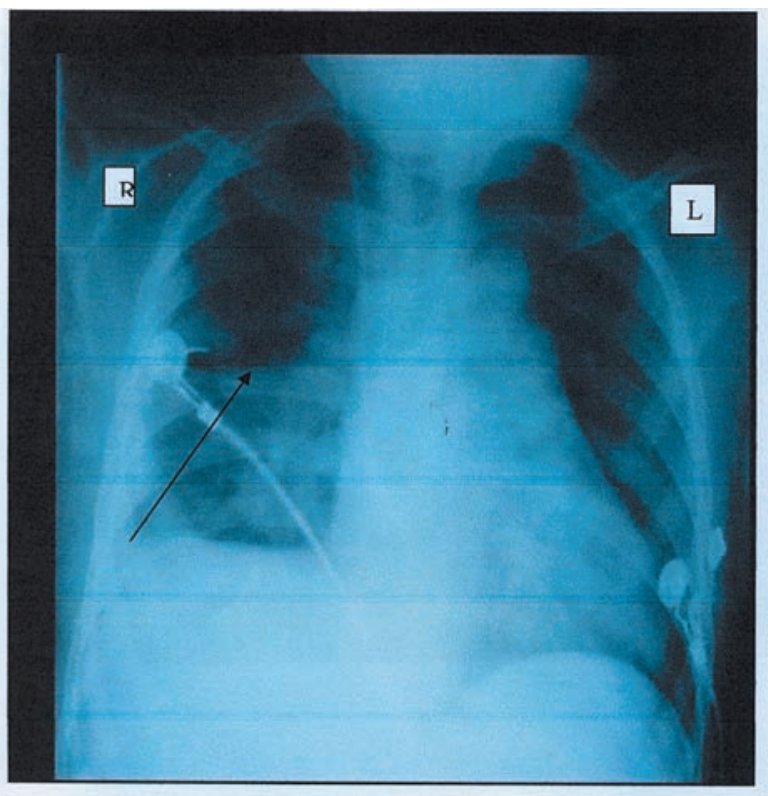

Figure 3

CT scan of the abdomen, arrows showing a diffuse hypodense right suprarenal mass with faint rim enhancement

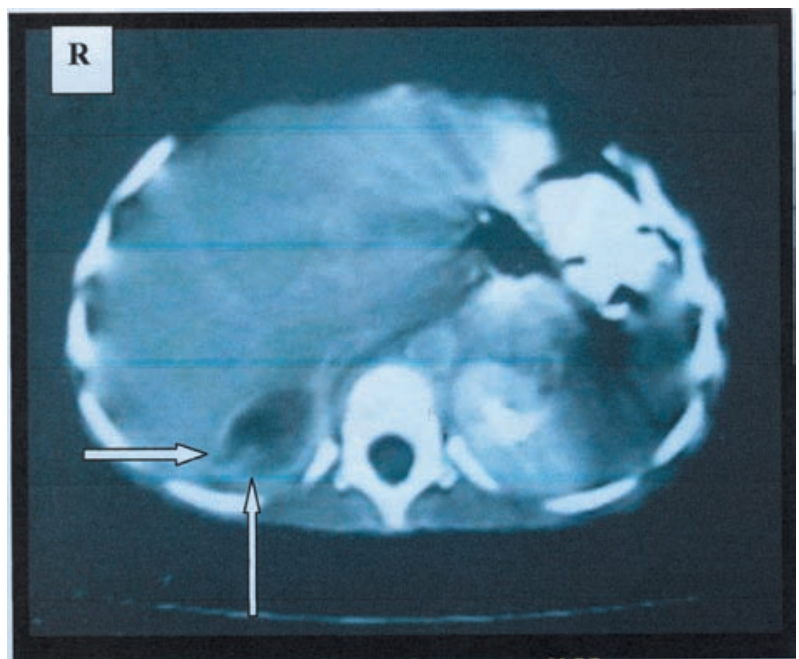

Figure 4

MRI images T1 and T2 images showing leucoencephalopathy of the occipital region suggestive of metastatic lesions

A

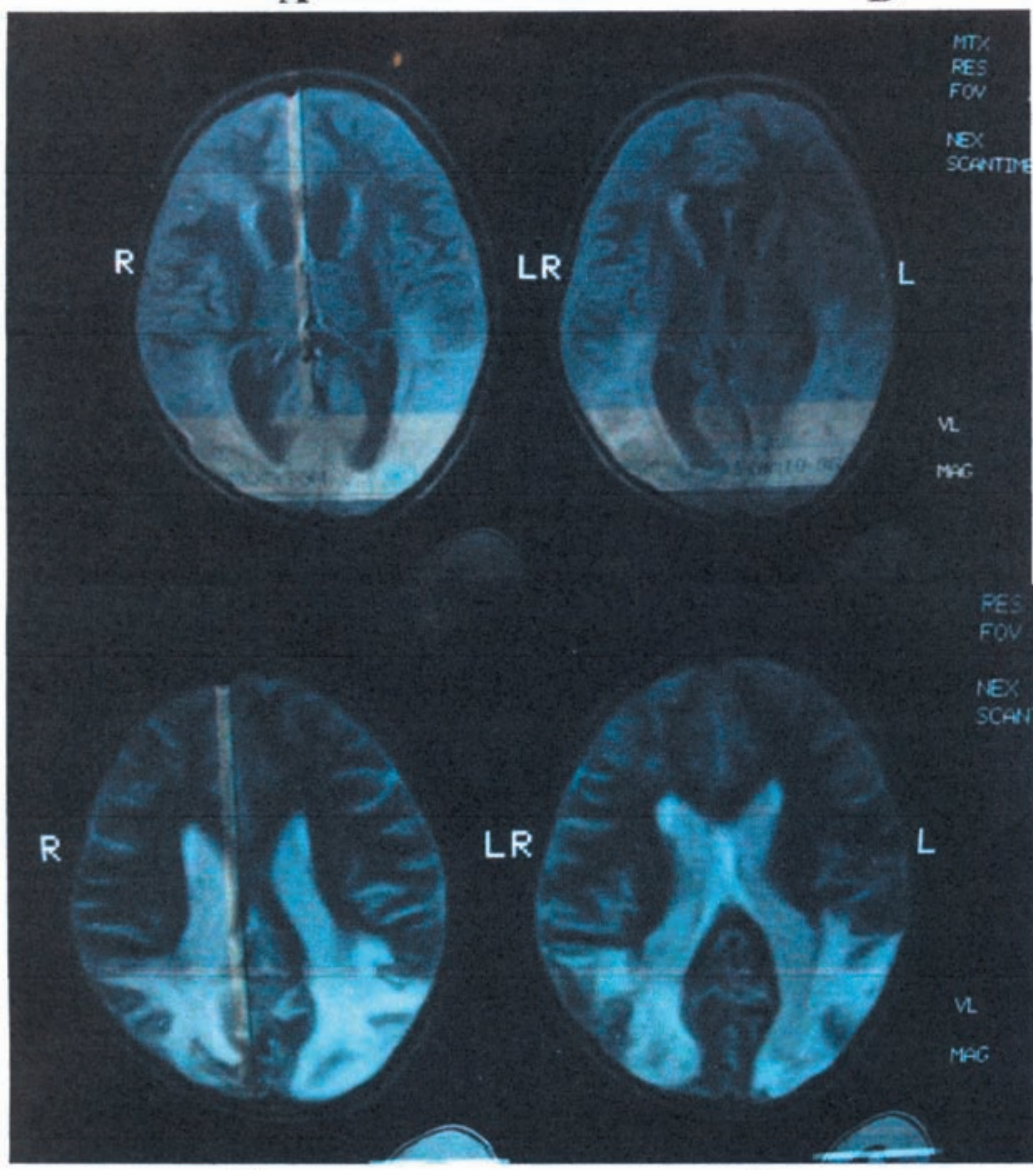

$\boldsymbol{C}$ 
A diagnosis of phaeochromocytoma was made and the patient started on alpha blockade with phenoxybenzamine and propanonol. All the investigationswere discussed at aclinical pathological conference and surgery was recommended. The supra renal and the thoracic tumours was removed via a laparatomy and thoracotomy. At surgery the thoracic tumour was situated along the sympathetic chain. Histology of the two masses showed pleomorphic tumour. During subsequent follow up a repeat thoracotomy was performed to remove recurrent thoracic masses.

Follow-up: Upon discharge from the wards the patient was followed by a team of doctors the neurologist for the recurrent convulsions, the nephrologists and paediatric cardiologist for the control of the blood pressure. The parentsboughtablood pressure machine for home monitoring. His blood pressures at any time were controlled with not less than five drugs and over the next four years he developed recurrent tonic clonic convulsions and was twice admitted in various hospitals due to status epilepticus. A repeat MRI at the ageof six years (Figure4) showed leucoencephalopathy with features suggestive of metastatic lesions. He finally succumbed at the age of seven years due to status epilepticus.

\section{DISCUSSION}

Phaeochromocytoma can mimic and can present with various clinical manifestations such as headache, sweating, palpitation, weakness or exhaustion, nervousness or anxiety, epigastric pain, blurring of vision, convulsions as reported in this case. An important mode of presentationishypertension, which may be paroxysmal or persistent $(3,8)$. In children, the course is often rapid and the condition may be provoked or accelerated even by minor trauma (10).

This case illustrates such a possibility, presenting with persistent hypertension following the initial insult by an infective process, with paroxysmal exacerbations. However, we were initially put off this diagnosis by the initial absence of hypertension and by the presence of normal catecholamine excretion levels, notwithstanding the fact that this patient had vasomotor phenomenon such as headache, sweating and abdominal pains. Sweating may be the only symptom suggestive of phaeochromocytoma as has been reputed in the past (8). Most of cases reported by Somers et al. (5) showed a female preponderance with a few occurring in pregnancy. A chest $X$ ray showed multiple right paracardiac masses (Figure 2) or autopsy showed the location of the tumour to be mostly in the right adrenal gland.

In the pre-operative medical management of phaeochromocy toma, it is endeavoured to reduce the blood pressure to a stable, lower level. Alpha-receptor blockade is the main component of this treatment.
Phentolamine is best suited for acute lowering of B.P whereas phenoxybenzamine must be considered better suited for long term pre-treatment. However, as it was with this case, several authors have reported difficulties in attaining the desired lowering of B.P so that supplementary treatment by B-blockers has been used with increasing extent. It even protects the heart from tachycardia and arrhythmia (11). In our case, these drugs did not give a stable B.P hence addition of calcium channel blockade and diuretic.

Multiple thoracic tumour involvement and poor blood pressure control necessitated a second thoracotomy to remove residual tumour masses. His intractable seizures could have been due to CNS tumours from which he succumbed.

\section{ACKNOWLEDGEMENTS}

To the parents of S.O., Dr. J.Munene and his surgical colleagues, the staff of paediatric wards, Kenyatta National Hospital. To Prof. S.O. McLigeyo for his insight during the diagnostic dilemma and management during the long follow-up period.

\section{REFERENCES}

1. Stackpole, R.H., Melicow, M.M. and Ucon, A.C. Phaeochromocytoma in children. J. Paed. 1963; 63: 315-330.

2. Virchows, et al. Arch Path. Anat.1965: 103: 244.

3. Robinson, M.J. and Williams, A. Clinical and pathological details of two cases of Phaeochromocytoma in childhood. Arch. Dis. Child. 1956; 31: 69.

4. St.John Sutton,M.A.,Sheps,S.A.andLie,J.T.Prevalence of clinically unsuspected Phaeochromocytoma: review of a 50 year autopsy series. Mayo Clin. Proc. 1981; 56: 354-360.

5. Somers, K., Shepherd, J.J. and Rwabugabya, R.G. Phaeochromocytoma in Africans; two recent cases and review of the literature. Trop. Geogr. Med. 1967; 19: 284-289.

6. Bloom, D.A. and Fonkalsrund, E.W. Surgical management of Phaeochromocytoma in children. J. Paed. Surg. 1974; 9: 179-184.

7. Parkar, A.R.T. Phaeochromocytoma; a case report and review of literature: East. Afr. Med. J. 1973; 50: 286-293.

8. Temleton, A.C. Phaeochromocytoma in East Africa: East Afr. Med. J. 1966; 44: 271-277.

9. Ross, E.J., Prichard, B.N.C., Kaufman, L., Robertson A.L.G. and Harries B.J. Pre-operative and operative management of patients with Phaeochromocytoma Brit. Med. J. 1967; 1: 191.

10. Boreus, L.O., Broberger, U., Nergardh, A. and Zetterquist, P. Malignant phaeochromocytoma in a child: Treatment with a combination of alpha- and betaadrenergic blockade. Act. Paediat. Scand. 1968; 57: 36.

11. McLigeyo, S.O., Otieno, L. S., Rana, F. S., Amayo, E. O. and Monda, S. M. Renal vein and intracaval invasion by an adrenal Phaeochromocytoma with extension into the right atrium: a case study. Afr. J. Hlth. Sci. 1996; 3: 60-63. 